\title{
A study on the bacteriological characterization of the coastal Tangier seawater: Preliminary results
}

\author{
Imane Bourouhou ${ }^{1, *}$, and Farida Salmoun ${ }^{1}$ \\ ${ }^{1}$ Laboratory of Physical Chemistry of Materials, Natural Substances and Environment, Faculty of Sciences and Techniques, \\ Abdelmalek Essaadi University, Tangier, Morocco
}

\begin{abstract}
This paper deals, on the one hand, with a study of bacteriological parameters of coastal water in the region of Tangier Ksar-Sghir, north of Morocco, and secondly, with an examination of the influence of temperature parameter on biological processes occurring within seawater. The bacteriological study concerns E. coli, fecal coliforms (F.C), total coliforms (T.C) and fecal streptococcus (F.S). A campaign of 25 sampling points spread over four layers of concentration was conducted in the coastal line during the year of 2017 and The overall results of tests were obtained using the Principal Component Analysis method. (PCA). The analysis has highlighted differentiated areas in term of sanitary quality. The highest values obtained were in the zone of Tangier-Med port showing high fecal contamination by pollution indicator bacteria (T.C, F.C, E. coli and F.S) with high temperature values that result in short-, medium- and long-term environmental pollution.
\end{abstract}

\section{Introduction}

The coastal environment is a natural heritage with great importance to our planet. Studies [1] show that the marine environment covers almost $71 \%$ of the total surface area of the earth, which shows the importance of this vast space in relation to continental environments. The complexity of this environment and the biodiversity it possesses demonstrates the fragile balance of marine ecosystems. Nowadays, there are some serious environmental problems menacing the quality of life in these areas. For instance, pollution, overfishing, climate change, overexploitation, etc. are still prevalent.

Morocco's coastline covers a large territory. According to MANSOUR (2003) [2], The Mediterranean coast spreads over a $512 \mathrm{~km}$ area and $93 \mathrm{ha} / \mathrm{km} 2$ over the distance knows economic and industrial activity. The wastewater of this region is disposed in the coastal waters without prior treatment [3].

In aquatic ecosystems, aquatic bacteria form a major component and are crucial to maintaining the ecological balance of these ecosystems. Microorganisms can have large-scale impacts, exceeding their environments (micro-habitat), microbial ecology often includes environmental microbiology that considers neither the environment nor biotic interactions [4]. As a result, the role of bacteria is fundamental to the ecological balance of aquatic environments.

The purpose of this study is to assess the level of bacterial contamination of coastal areas based on various sanitary quality parameters of coastal waters of the Tangier-KsarSghir region. In terms of health, the bacteriological quality of seawater, according to
BONNEFONT et al. (1990) [5], is assessed by the examination of bacterial infections (essentially fecal coliforms and fecal streptococci). The results of the analysis are summarized by the Principal Component Analysis statistical method.

\section{Materials and methods}

\subsection{Study area}

The Moroccan port of Tangier Med is located in the northern Region of Tangier-Tetouan-Al Hoceïma (Fig. 1). It was built between 2004 and 2007. Its main activity is the transshipping of containers.

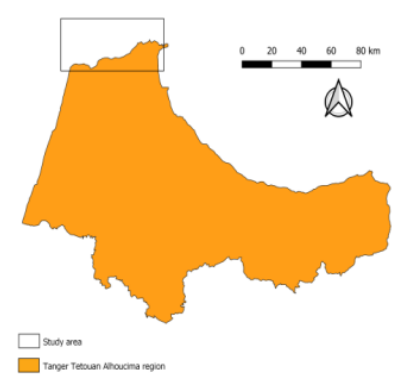

Fig. 1. Geographical location of the study area

The port is connected to more than 120 ports in 50 countries worldwide, to which it is connected by regular weekly lines. Geographically, the port is positioned on the

Corresponding author: ibourouhou@uae.ac.ma 
East-West route of world maritime trade, between Asia, Europe and North America, which is considered the second most common shipping line in the world with more than 100000 ships per year.

\subsection{Sampling and analytical technique}

Following the study of the scope, it was thought appropriate to choose the stratified random sampling technique. The non-homogeneity of the longitudinal distribution related to the dispersion of the pollution considered one-off in an area characterized by a high pollution gradient. Therefore, simple random sampling is inadequate for this study. On a coastline of $54,5 \mathrm{~km}$, pollution is concentrated in the port region. The estimate of the overall quantity will be biased if random samples ignore high concentration areas [6].

Using stratified sampling, the coastline is divided into areas of different concentrations (strata). In each stratum, the sampling was more or less proportional to the pollutant load, which makes it possible to specify the average and to minimize the variance of the estimated average.

In summary, the method consists of identifying the study area and divide it into strata of known lengths, each corresponds to a type of concentration. The samples are taken randomly from each stratum. Finally, by weighting the averages and variances, an estimate of the overall mean is obtained.

Areas are chosen in terms of geographical accessibility and the size of the strata takes into account the shape of the regions (presence of ears, artificial beaches, etc.). The division of the strata is based on the prior knowledge of the different areas classified according to an indicator of the level of pollution in a previous study carried out by the Ministry of Energy, Mines, Water and Environment in collaboration with the Ministry of Equipment, Transport and Logistics, responsible for the environment [7]. The study carried out during the period of May 2015 to March 2016 [8], aims to assess the quality of bathing water in supervised beaches. It concerned the examination of microbiological parameters, fecal coliforms (Escherichia Coli) and enterococci (fecal streptococci) in accordance with the national standard on this subject ( $\mathrm{Nm}$ 03.7. 200), transposed from the European Directive (76/160/EEC) and the OmS/UNEP Guidelines for the Health Surveillance of Marine Bathing Waters.

The strata will be identified according to the four categories defined by the pollution level indicator so that our study area is divided into homogeneous sub-areas prior to sampling. The Tangier Med port region is identified as the area with the highest concentration since it represents the main source of pollution and this does not prevent the existence of specific sources of pollution in other areas from discharges of sewage, river mouths, etc. In fact, in the monitoring program carried out jointly by the Ministry of Equipment, Transport and Logistics and the delegated Ministry for the Environment, monitoring sites are chosen based on the size of the use, the nature of the site (relief, shoreline shape, etc.) and the particular risks of pollution (sewage discharge, river mouth, ports, etc.).

The assessment of coastal water health shall be based on microbiological parameters established by arrangements for monitoring the quality of marine waters in compliance with the national standard on marine water quality (Nm 03).7. 200), transposed from the European Directive (76/160/EEC) and the OmS/UNEP Guidelines for the Health Surveillance of Marine Bathing Waters. The study focus on four germs, which are indicator organisms of fecal contamination: fecal coliforms, total coliforms, Escherichia coli and fecal streptococci. Based on studies by FIGARELLA et al. (2001) [9] and LARIF et al. (2013) [10], these germs are of little or no pathogen, they are indicative of fecal contamination and lead by their abundance to the presumption of more dangerous contamination.

The sample shall be analyzed immediately after sampling. The sampling step directly influences the results of bacteriological analyzes. In order to avoid contamination, special precautions were taken during sampling and storage in accordance with ISO 5667-1, ISO $5667-2$ and ISO 5667-3. The maximum storage time for samples for analysis shall be 24 hours provided they are kept at a temperature of 5+/- $3 \mathrm{C}$.

The examination consists of membrane filtration followed by culture in a differentiation agar and calculation of the number of target organisms in the sample. The method of calculation adopted by this analytical protocol refers to the NM ISO 7218 where the specific procedure for calculating the number of units forming colony PS.MA.-5.4-08. To count in the agar medium, each isolated bacterium is indicated by the existence of a colony forming unit (CFU). The number of bacteria present in the test sample is calculated by calculating the typical colonies in all Petri boxes for successive dilutions.

\subsection{Data processing}

The assessment of the microbiological quality of coastal seawater in the Tangier Med harbor region is based on a statistical approach that uses the principal component analysis (PCA) method for the overall estimation of sanitary pollution in this region. The PCA is a descriptive statistical method whose objective is to present, in the form of graphs, the maximum of the information contained in a data table [11] [12].

\section{Results and discussion}

\subsection{Bacteriological analysis}

The samples were taken along the Mediterranean coast in the region of Tangier-Ksar Sghir. twenty-five stations were selected for bacteriological analysis. The multivariate analysis was used to describe the summary of information contained in the bacteriological parameters variables in the Tangier-Ksar sghir seawater. The purpose of this analysis is to link the various variables (total 
coliforms, E. coli, fecal coliforms and fecal Streptococci) by correlation. Results are combined in a 25-line matrix representing observations and 4 columns representing variables. The two main axes F1 and F2 represent the own values and their contribution to the total inertia of the analysis.

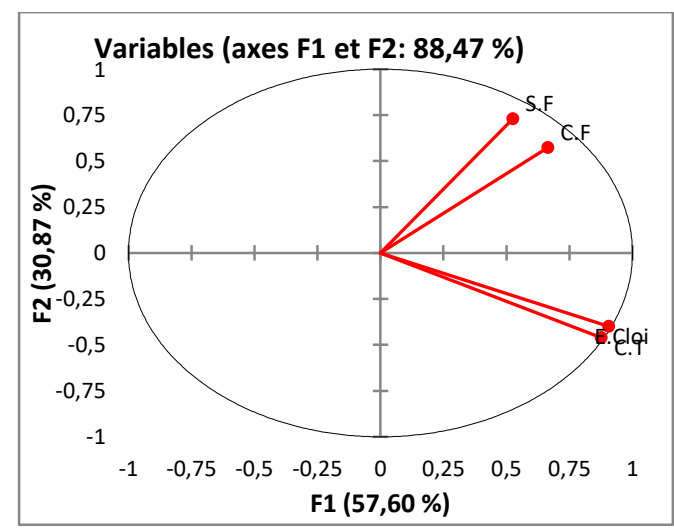

Fig. 2. Representation of the variables according to the factorial plane F1 and F2 inside the correlation circle.

The correlation circle (Fig. 2) shows that fecal streptococci, fecal coliforms, Escherichia coli, and total coliforms all contribute positively to the formation of the F1 axis, which explains $57.60 \%$ of the total variance of the data (Fig. 3). Fecal streptococci and fecal coliforms contribute positively to the formation of the F2 axis, which explains $30.87 \%$ of the total variance, whereas Escherichia coli and total coliforms contribute negatively.

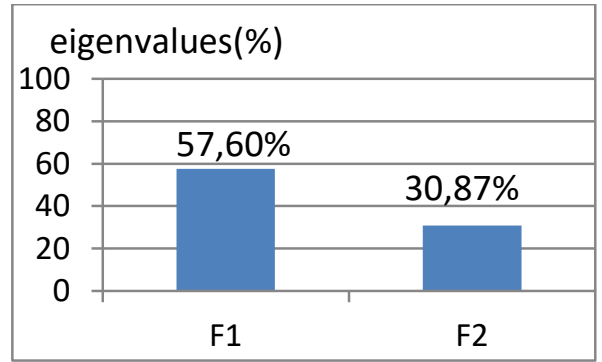

Fig. 3. Representation of the factors F1 and F2 based on the eigenvalues

The two F1 and F2 factors (Table 1) represent a factorial map of data variability of $88.47 \%$, which overlooks other factors. Therefore, the review of the PCA will be done on the basis of these first two factors (Fig. 4).

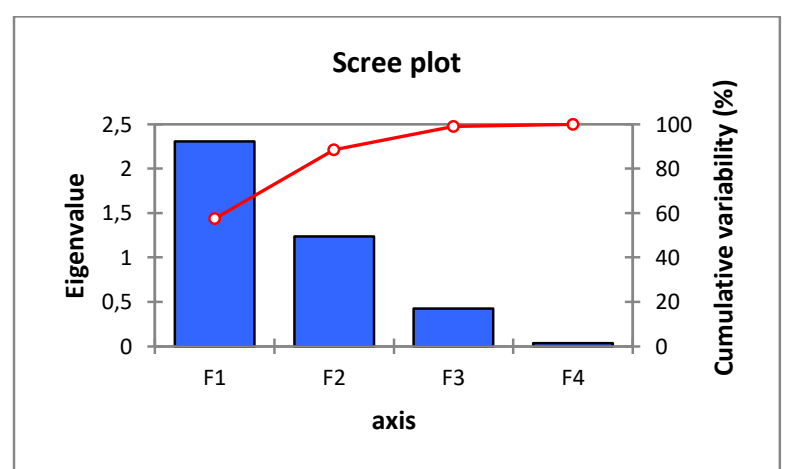

Fig. 4. PCA graphical approach: Representation of cumulative variability of the PCA axis
Table 1. Table of variability and cumulative variability of the axis

\begin{tabular}{|c|r|r|r|r|}
\cline { 2 - 5 } \multicolumn{1}{c|}{} & \multicolumn{1}{c|}{ F1 } & F2 & F3 & \multicolumn{1}{c|}{ F4 } \\
\hline Eigenvalue & 2,304 & 1,235 & 0,424 & 0,037 \\
\hline Variability (\%) & 57,603 & 30,868 & 10,612 & 0,917 \\
\hline Cumulative \% & 57,603 & 88,472 & 99,083 & 100,000 \\
\hline
\end{tabular}

The graph of the observations makes it possible to identify trends in sampling sites. Based on the factorial map F1 x F2 (Fig. 5), PCA results show that the different stations on the right side are the most polluted while those on the left side are the least polluted.

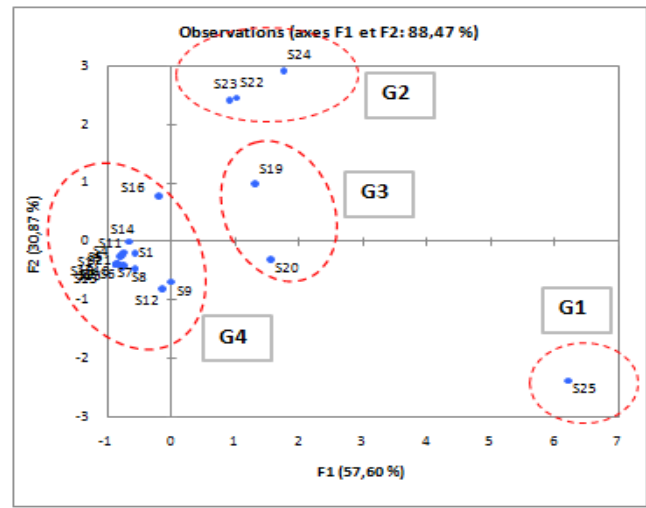

Fig. 5. Representation of sampling sites on factorial plane F1 and F2

The overall analysis by factorial projection of individuals (F1, F2) reveals four groups of pollution levels:

Group 1 (G1): Based of four variables, the S25 site presents itself in a rather particular way: S25 is characterized by very high values of the four bacteriological parameters studied. This site is positions at the level of stratum IV in the sampling area of the Tangier-Med port. These values reflect the presence of very high fecal contamination in this region. The site is also characterized by a very high value of the bacteria Escherichia coli. Recent studies [13] show that detection of the E. coli indicator is indisputable evidence of the occurrence of recent fecal contamination and indicates the potential presence of enteric pathogens. The various human enteric viruses released to wastewater are highly resistant in the outdoor environment and can persist with treatment and then be found in surface water, coastal water or food [14].

Group 2 (G2): The S22, S23, and S24 sites also in the Tangier-Med harbor area are characterized by significant fecal pollution, represented mainly by the two types of bacteriological pollution indicator germs: fecal coliforms and fecal streptococci [15]. According to the report of the Mediterranean Tangier Special Agency (2010), the presence of these bacteria in the Tangier-Med port region could be linked to the fact that the bacteria of fecal origin resulting from discharges from ships are among the pollutants characteristic of port areas. The existence of total coliforms reflects the presence of environmental contamination in the region. 
Group 3 (G3): At the two sites of Tangier city S19 and S20, the water quality is of poor quality. Fecal coliform values are particularly high at both sites compared to [1] adjacent areas (Marqala beach and Tangier-Malabata beach); the water taken contained 1,5.103 fecal coliform CFU/100 $\mathrm{ml}$ and 10,4.103 CFU E. coli $/ 100 \mathrm{ml}$. These polluted stations are affected by discharges of sewage into the sea.

Group 4 (G4): This group comprises sampling sites characterized by medium quality water and the mandatory number laid down by the European Directive (76/160/EEC). For E. coli and fecal coliforms is respected in at least $95 \%$ of samples.

\section{Conclusion}

A study of the bacteriological parameters of the waters of the Mediterranean Sea at the shoreline of the Tangier Med harbor was carried out in the context of monitoring and assessing the quality of coastal waters at the level of the Tangier-Ksar Sghir region. Values obtained from water analysis in the study region indicate high fecal contamination by pollution indicator bacteria (CT, CF, E. coli and S.F) with high temperature values that result in short-, medium- and long-term environmental pollution. The microbial quality of the waters of Tangier city beach is mediocre and shows high values of fecal coliforms that exceed the mandatory standards of bathing water. These results indicate that this water is influenced by wastewater discharges from the city's sewage system. The rate of fecal load in other coastal areas remains of average quality with values that exceed the guideline values of bathing water quality but with respect for the number imperative.

\section{References}

1. Ronday F., Beckers J.M, «Physical Oceanography, local description of the oceans. preliminary version,» Liege, (2005).

2. Mansour. M., «TS7 Coastal Zone Managment,» chez 2nd FIG Conference, Marrakech, (2003).

3. Blinda. M., Pollution tellurique du littoral nord-ouest du Maroc entre Tanger et Tétouan: Caractérisation, Impact sur l'Environnement et Proposition de Solutions [thèse]., Rbat: Mohammed V University, Faculty of Science, p. 17. (2007),

4. Bouef. D., Importance écologique des bactéries photohétérotrophes dans l'océan arctique., UPMC Sobronne University, p. 12.(2013),

5. Bonnefont J. L., Martin Y. P. \& Guiennet B., War. Res, vol. 24, n 13, pp. 267-273, (1990).

6. Loubersac L., «Pollution of the French coastline by macro-waste,» (1982).

7. Ministry of Equipment, Transport and Logistics Morocco. Ministry Delegate to the Minister of Energy, Mines, Water and Environment, in charge of the Environment Morocco., «National report. Monitoring the quality of bathering water,» Rabat, Morocco, (2015-2016).
8. Ministry of Equipment, Transport and Logistics Morocco. Ministry Delegate to the Minister of Energy, Mines, Water and Environment, in charge of the Environment Morocco., «Analytical report. Monitoring the quality of bathering water,» Rabat, Morocco, (2015-2016).

9. Figarella J., Leyral G. \& Terret M., Applied and General microbiology, Jacques Lanore, p. 285, (2001),

10. Larif M., Soulaymani A., El Midaou A. \& Hnach M., Int. J. Biol. Chem. Sci, n 17, pp. 172-184, February (2013).

11. Philippeau G., «How to interpret the results of a principal component analysis., Paris, (1986).

12. Mounjid J., Cohen N., Fadlaoui S., Belhouari A. \& Oubraim S., «Contribution à l'évaluation de la qualité physico-chimique du cours d'eau Merzeg (Périurbain de Casablanca, Maroc),» Larhyss Journal ISSN 1112-3680, n 118, pp. 31-51, Juin (2014).

13. Verhille, «Microbial indicators in the assessment of drinking water: interpreting laboratory results and understanding their significance for public health,» Canada, (2013).

14. Le Guyader F.S., Ollivier J., Le Saux J-C. \& Garry P, «Human enteric viruses and water,» Francophone Review of Laboratories, $n^{\circ} 1459$, pp. 41-49, February 2014.

15. Mehanned S., Zaid A. \& Chahlaoui A., Larhyss Journal ISNN 1112-3680, $\mathrm{n}^{\circ} 117$, pp. 215-225, (2014).

16. Blinda. M, Pollution tellurique du littoral nord-ouest du Maroc entre Tanger et Tétouan: Cavacrétisation, Impact sur l'Environnement et Proposition de Solutions, Rabat: Mohammed V university, Faculty of ciences, p. 17, (2007),

17. C. a. H. Ministry of Industry, «Moroccan standard NM 03.7.200: Standard for monitoring the quality of bathing water,» (2016).

18. T. M. S. A. (. Creocean, «Port complex extension project (Tanger Med II), Environmental Impact Study, final version.,» (2010).

19. Collegiate of teachers of bacteriology-virologyhygiene, Growth of bacteria, French Virtual Medical University , (2014).

20. Chaouay A., Okhrib R., Hilali M., Bazzi L., Chahid A. \& Khiri F, pp. 2748-2759, (2016). 